\title{
Sociological Approach to Modeling the Quality of Higher Education
}

\author{
Alikarieva Alokxon, \\ assistant professor of Sociology, Phd \\ National University of Uzbekistan \\ named Mirzo Ulugbek, Department of Sociology \\ Tashkent, Uzbekistan, alohon@mail.ru

\section{Turatosheva Sadoqat,} \\ Basic doctoral student \\ Mirzo Ulugbek national University of Uzbekistan, \\ Department of Sociology
}

\section{ANNOTATION}

The article analyzes the specificity of sociological modeling of higher education. The article deals with the conceptualization of the sociological model of quality higher education in the context of different methodological approaches. In particular, it points to the relevance of addressing the sociocultural dimension of quality. The article examines the procedural characteristic (the effectiveness of the educational process) as the degree of the ratio of the goal - means - the result of the organization of the educational process, which is evaluated in terms of the activity of the collective subject of the educational process. The sociological model of quality is considered from the standpoint of such indicators as literacy, education or competence obtained on the basis of key competencies. They also consider their method of integration, based on the selection of conditional types of culture in the process of professional formation of the personality, each of which, having its own specifics, presupposes a hierarchically organized interaction.

\section{Keywords}

quality of higher education, sociological model of quality of higher education, efficiency of the education process, sociocultural approach.

\section{Introduction.}

Today, higher educational institutions have become full-fledged subjects of the market economy, having received the right to independently determine the directions of their development, goals and methods of achieving them. The requirements of society for the quality of education have increased, teaching technologies are being radically updated, the organizational and economic conditions of the activities of universities are rapidly changing, the competition in the educational services market is intensifying, the position of the state in relation to higher education is constantly changing. The state abandoned the role of the main and only financier of higher education. Different groups of customers and consumers of educational services have emerged with their own financial capabilities, requests and interests. Non-state universities have appeared and are successfully developing, which leads to competition in a number of opportunistic specialties. The growth of independence and freedom of universities has led to an increase in the responsibility of universities for the 
effectiveness of their activities. The focus of many universities on survival requires serious changes in the processes of university management, since the traditional methods of management in market conditions have proved to be untenable in some cases.

- To solve the problems of adaptation, survival and development in the new conditions, universities must not only constantly monitor the state of the educational services market and assess their position in this market, but also apply methods of forecasting market development, develop alternative options for their future behavior depending on changes in the external environment, those. use strategic approaches in the regulation of their production and economic activities.

- Today, almost all rectors understand the need to apply the strategic management of the university, but still there are not only practical recommendations for the implementation of strategic management in the university, but also a comprehensive theoretical approach to solving these problems. A significant volume of publications and training manuals is devoted to the issues of strategic management of an enterprise or organization.

- Modern approaches to the university management system require the creation of an information system and a database that facilitate decision-making in the event of various current situations. As a rule, the bearers of this knowledge are unsystematic documents and employees, whose status may change, which will lead to the loss of information. In addition, the solution of complex problems with the participation of many people is inevitably delayed due to the load on them with parallel works, various personal interests, etc. The presence of a knowledge base can significantly increase the efficiency and validity of strategic and tactical decisions.

- New management processes that flexibly respond to changes in the current situation in the operational and strategic terms and use for this the entire available arsenal of information technologies, should provide the ability to quickly analyze:

- - ways to improve the organizational structure of the university management;

- - problems and conditions for sustainable development of the university;

- - ways to optimize financial flows;

- - infrastructure and investment opportunities of the university;

- - extreme situations.

- In strategic management, the need to quickly process a huge amount of external and internal information requires the development and implementation of an information system in the management of the university, which will allow the rector to:

- - receive a continuous, objective picture of the state of the university as a whole and its structural units;

- - to identify trends in the development of the university, i.e. to understand what the university will come to in the future, if there are no cardinal changes;

- receive answers to the questions "what will happen if";

- conduct risk assessment;

- track changes in the external environment and its impact on internal processes: educational, research and auxiliary;

- plan and conduct current production meetings on an expanded information and analytical basis.

The information system of strategic management of the university consists of the following main parts: 
- portal that provides visualization, search and input of external and internal information;

- data warehouse (knowledge base);

- simulation modeling systems. The information system of strategic management of the university should provide:

- an interactive mode of formalizing knowledge about the goals and strategy of the university, the external environment of the university and the processes of the university;

- description of the organizational structure and analysis of the quality of the distribution of functions;

- assistance in the development of models of educational processes, models of the movement of financial, material, labor and information types of resources;

- analysis of consolidated characteristics of processes, including functional and cost analysis;

- carrying out simulation experiments with dynamic models of processes.

The presence of an information system will allow formalizing production processes, as well as providing the ability to predict the movement of all types of resources, including material, energy, information, financial and labor flows; more clearly define the list of educational services and the behavior of market participants, ways to increase the volume of educational services, improve the image of the university; justify the need for structural changes. The rector, using the information system, will be able to receive summaries presented in the form of tables, graphs, maps on the screen of his computer monitor in the most convenient and informative state. In addition, various animation fragments that characterize the controlled processes can be displayed on the screen. The information system will provide answers to the following questions:

- how things are going at the university;

- what happens to the external environment and how it affects internal processes;
- "what will happen if" (forecast of the results of management decisions).

When answering the first question, the main indicators characterizing the activities of the university are reflected on the monitor screen:

- financial condition of the university;

- human resources;

- reception status;

- academic performance;

- condition of buildings and structures, land plots of the university;

- quality of educational services;

- university rating;

- regulatory documents;

- etc.

The analysis of the external environment is based on the factors that have the greatest impact on the work of the university: customers, suppliers, competitors, financial institutions, etc. To answer the third type of questions, the rector is provided with tools for modeling the activities of the university [1, - p. 38] ..

Analysis of the relevant literature. The process of transformation of the higher education system is taking place under the sign of an ever more profound paradigmatic confrontation between nocratic ideas about the possibilities and main directions of reforming higher education and the need for its humanitarian rethinking. This is fully manifested in the approaches that are incorporated in the corresponding systems for assessing the quality of the educational process (faculty, number of publications, equipment of educational units, etc.). None of these parameters, as well as their totality, makes it possible to clearly define the sociocultural component of intellectual potential as an objective factor that affects the quality of the educational process. Objective factors that can significantly change the quality of education can be the way of organizing the educational process in unity with the state of professional and pedagogical culture. But they are not adequately reflected in the proposed 
educational standards. This circumstance determines the real state of affairs in the educational space of higher education.

Thus, the main criterion for the quality of higher education is its compliance with state standards, which fix social needs for specific competencies, while the internal basis of the quality of higher education is contained in the axiological dimension of the latter. In this sense, the quality of higher education is an explicative, formative and consolidating means of organizing the system of values of education of the new era, and today there is a gradual affirmation of a new quality of education, which is characterized by ideas and principles opposite to the scientific and technocratic paradigm. Therefore, a necessary condition for ensuring the quality of higher education today is the interactive relationship of the subjects of the educational process, the main means of forming an effective educational space is dialogue, and the determining principle of ensuring the quality of the educational process is its dialogic nature, according to one of the researchers of the quality of education Kisil M.V. [2, - C. 28]. That is why, according to the scientist, the need for humanization and humanitarization of higher education is being actualized with renewed vigor, which can be fully realized through such ideas of the modern paradigm of education as fundamentality, integration, existentialism, competence, selectivity, individualization, specialization, complexity, polyprofile nature, cyclicity [2, - p. 29].

Considering these points, it should also be noted that the conceptualization of the problem of high-quality higher education is influenced by the processes taking place in the educational space, so the latter become an integral part of the philosophical analysis of the quality of higher education. So, in the normative terms, the principles and means of ensuring the quality of higher education are fixed in the Bologna
Agreements, which define the quality of higher education itself, on the one hand, as a goal, and on the other, as a basis for creating an educational space.

In the presence of a huge variety of models of higher education in the country, the problem of ensuring its quality can be solved only by resolving the contradictions between two opposite tendencies - preserving national uniqueness and identity and striving for unification. Probably, in this regard, the model for providing quality education will be inclined towards the creation of such procedures for assessing the quality of education, which are inherent in the signs of relativity, adaptability, and universality.

The quality of higher education arises, on the one hand, as an attributive characteristic of higher education, and on the other, as an integral product of the development of science and culture, which meets the actual needs of the development of society [3, - P.14]. At the same time, the essence of the quality of higher education is defined by the researcher as the total energyinformational potential of a person, which she accumulates in the process of studying at a higher educational institution, and its content is manifested by the innovative nature of the productive activity of a specialist and is revealed in objectified and subjective forms. It is in this context that the problems of modern higher education motivate the problem of conceptualizing the sociological model of the quality of higher education. Indeed, considering the problem of modeling quality education as such, it is possible to determine what, in the end, society expects from higher education, to prevent new and understand existing problems.

In an effort to get out of the narrow circle of quantitatively verifiable indicators of the qualitative essence of education, sociologists resort to modeling. The appeal to modeling, according to Aninkova M.A., testifies to the relevance of the appeal to the socio-cultural 
measurement of the quality of education in its proportionality with such concepts as the image, style and quality of life. After all, the essence of the quality of education lies in the fact that it acts as a way of the relationship between education and society, as well as a criterion for the proportionality of the results of a person's educational movement in the cultural and educational space and the educational needs of society [4].

Research methodology. As far as the higher education system itself is concerned, by now, in the scientific environment and among practical workers of higher education, various interpretations of the concept of the quality of education have developed, which are built on the basis of a different structural combination of such categories as "education standard", "educational result", "quality of the educational process ", etc. In this case, the semantic understanding of the basic concept changes significantly. So, some consider this category as purely managerial, linking it with the mechanisms and conditions for the normal functioning of the university. This position is rooted in the theory of management of educational institutions that has been actively developed recently. Others suggest focusing on the quality of training; still others - on the quality of educational standards, curricula and textbooks for universities; the fourth - on the problem of the organization of the educational process and the quality of its scientific and methodological, information, personnel, material and technical support.

From this point of view, we agree with $\mathrm{M}$. Anninkova that "the quality of education cannot be reduced to such results as literacy, education or competence obtained on the basis of key competencies. It is necessary to find a way to integrate the above concepts, considering them as certain levels of achieving the quality of education "[5, - p.50-58]. It should be agreed that the concept proposed by the famous Russian scientist
M.S. Kagan can be a productive approach to solving this problem. It is based on the identification of conditional types of culture in the process of the professional formation of the personality, each of which, having its own specifics, presupposes hierarchically organized interaction. In this case, each type of culture should correspond to a certain integrative quality that characterizes the result of individual advancement in this type of culture [6, - P. 28].

Thus, the level of literacy is quite consistent with the "culture of the erudite", in which cognitive activity dominates, manifested in the extremely wide accumulation of knowledge. The level of competence is adequate to the "culture of practice", since it is built on the dominant of transformative activity, which presupposes an ascent to its highest form creativity. Therefore, it is such a professional skill that liberates the intellectual capabilities of the individual and allows you to bring something fundamentally new to the labor process. The level of education is a product of the "culture of a moralist", where value-orientational activity dominates, organizing the core of value orientations that normalize all the activities of the individual. Further climbing the steps of the types of individual culture is associated with the "culture of a sociable person", the systematizing factor of which is the desire for perfect human relationships.

This level, which generalizes all the previous ones with human essence and fills with meaning the integral space of culture, is quite comparable with such quality as mentality, rightly defined as "the quintessence of culture". Such an approach, according to Anninkova MA, makes it possible to most fully represent not only the "collapsed socio-cultural genesis of the process of the professional formation of an individual", but also to find a way with which one can "remove the contradiction between its general cultural and professional components", a contradiction that is 
the most vulnerable spot in the higher education system. Its lack of resolution in the existing system divides the concepts of "person with higher education" and "intellectual" rather far [7, p. 159].

From this point of view, the approach proposed in the works of I.A. Zimney, based on a deep understanding of the dialectics of the two sides of the educational process in higher education from the standpoint of the modern paradigm of education, is very productive. "The general culture of a person, notes I.A. Zimnyaya, is a way of his social life, social life, revealing the entire set of knowledge, values, traditions assigned to them in the process and as a result of their" de-objectification "and subsequent" objectification "and manifests itself in all forms his behavior.

Socio-professional competence is a quality formed on the basis of a person's general culture, which provides the ability to solve social and professional problems adequately to the arising regular and emergency situations in social interaction and professional activity. At the same time, each partial social competence that is part of a single social and professional competence manifests the full potential of a person's general culture. In other words, if the general culture of a person is a socially determined way of his life, then social and professional competence is a projection of this way to a certain sphere, area of activity" $[8,-$ p.19].

The proposal of N.A. Selezneva to understand the quality of higher education in a broad sense is also systemic at the level of the institutional approach to the definition:

a) "balanced correspondence of higher education (as a result, as a process, as an educational system) to diverse needs, goals, requirements, norms (standards)";

b) "a systemic set of hierarchically organized, socially significant essential properties (characteristics, parameters) of higher education (as a result, as a process, as an educational system)."

Attention is drawn to the attempt to integrate the two-address nature of the quality of education, thereby solving the dilemma of the orientation of the educational result: "society personality" [9, - P.19-27]. This approach finds its continuation in a conceptual model based on the isolation of three levels of the higher education system: macro-, meso- and micro levels. They correspond to the levels of definition of the quality of education: the state-regional (predicted and desired from the position of the state, the quality of education), the level of the student (the quality of the educational process in a given university at a given time) and the level of the student (the quality of higher education actually received by the graduate of the university). We can agree with the assessment of the author of this model that such an "approach to the problem of the quality of education allows one to obtain systematic, rather than scattered data on the level of training of specialists and makes it possible to conceptually study the problem of quality and ways to solve it at various levels" ], add, taking into account their specifics. Another significant condition, according to the researcher, is the need to differentiate the components of this model on the basis of "process - conditions (factors)" and "state - result".

A number of researchers note that they are unequal in terms of their share in providing high quality education, while considering it necessary to differentiate them. In particular, T.A. Yakovleva proposes to highlight the group of factors that affect the quality of the resource potential of the university, which, in turn, is subdivided into the quality of the subjective component (for example, the quality of scientific and pedagogical personnel) and objective ("material" material and technical base, etc.) component. A similar approach, in a slightly different interpretation, is incorporated in the current documents on the certification of higher 
educational institutions. It has become quite traditional [11]. On the other hand, the experience of educational institutions indicates that the main factor determining the quality of education is the educational process as a process of interaction between the teacher with his professional and pedagogical culture, and the student, with his motivation and readiness to participate in the process of education and educational content. ...

In the study and analysis of socioeconomic factors affecting the effectiveness of teachers' work, one of the most important points is to identify the significance of the influence of certain factors in their overall totality on the effective indicator. In practice, this is very difficult. The task is facilitated if you can use the method of analysis of variance, which is one of the branches of mathematical statistics.

Analysis of variance is the identification and assessment of individual factorial traits that determine the variability of the effective trait. Each factorial feature varies in the total set of units. The accepted method of measuring and analyzing the variation of these features is the basis of analysis of variance as a method for studying the significance of factors [12, - P.948] ..

Thus, for the socio-cultural discourse of designing a model of the quality of education, taking into account the already indicated positions, it makes sense to separate the concepts of "efficiency" and "effectiveness" of the educational process, while adhering to the following beliefs:

- the effectiveness of the educational process (procedural characteristic) as the degree of the ratio of the goal - means - the result of the organization of the educational process, should be assessed in terms of the activity of the collective subject of the educational process. A collective subject is understood as "a community of teachers and students, united by common value and semantic guidelines for vocational training, implemented in the integral educational process - its target, content and technological components" [10, - p. 43];

- the effectiveness of training is actually the degree of readiness of the graduate for professional activity as a result of achieving the fixed goals in the image of the graduate model. At present, the level of performance is mainly judged by the degree of approximation of indicators to the state or subjectively established educational standard).

An integrative performance indicator characterizing the quality of education is nothing more than a "graduate model" in the degree of its approximation to the demanded "model of a specialist" and the concept of "qualification characteristics of a specialist with a higher education", which is more used when working with standards. It is clear that any model, no matter how multifactorial it may be, is as different from a real specialist as a dummy is from a living person, since it simplifies the phenomenon itself [7, - P. 163].

In general, the model of a specialist's activity as a research apparatus should have certain properties and be based on certain principles that ensure the achievement of the set goals. Obviously, it should be, firstly, adequate to reality, that is, to ensure the maximum correspondence between the assigned task and the practical activity of a specialist.

Second, the model must be dynamic. The latter is understood as its periodic reproducibility, due to which a continuous reflection of the changes taking place in society can be achieved. It is this property of the model that can ensure its compliance with modernity and competitiveness in the labor market. In this sense, the factors of the model will be the quality of education of a student and a specialist, and the level of knowledge and needs of the applicant will also significantly affect. If we take as a basis the position that highquality education is personality-oriented, creating conditions for the development and creative self- 
realization of each applicant, increasing the potential of gifted children and youth, then the main attention in the model should be paid precisely to the needs of a person who wants to get a higher education [11, - S. 755-759].

Conclusions and suggestions. These points are basic when creating a model, because in the context of modern transformational changes, it is necessary to form a new sociological model of the quality of education, adapted to constant transformational processes. The sociological model of the quality of education appears in its spatial and temporal expression as multilevel (macro, meso, micro) and multidimensional (who, where, how, what to teach). The main principle of its organization is the principle of what is necessary and sufficient, so that, without losing the integrity of the definition, be able to find the parameters of its sociological interpretation adequate to this integrity. The main way to determine the degree of sociocultural orientation of the education quality model is a paradigmatic approach to determining the type of education, based on the degree of manifestation of the sociocultural triad "society - culture - person". The quality of education, being an integral degree of its cultural content, is determined by the quality of the content of education, the quality of educational means, the quality of the educational process and the quality of the result of educational activities [9].

Summing up, it should be noted that the article analyzes the main basic provisions of the conceptualization of the sociological model of the quality of education, which, of course, are still largely debatable. The main conclusion is the assertion that the socio-cultural dimension of the quality of education cannot be distanced and considered in isolation from concepts such as style and quality of life, educational need, etc., since the quality of education is a criterion for the proportionality of the results of a person's educational movement in cultural and educational space and educational needs of society, the way of the relationship between society and education. The conceptual foundations for the creation and effective functioning of the sociological model of quality in higher education provide for the formation and modernization of such key elements of this system as the philosophy of educational standards for higher education, monitoring of education, the quality of subjects of the educational process, rating in higher education, modernization of traditional means of quality assurance.

\section{Reference:}

1. Councils B.Ya., Yakovlev S.A. System Modeling: Textbook. for universities. 4th ed., M .: Higher. shk., 2017 .-- 343 p.

2. Kisil M.V. The quality of higher education as a subject of philosophical analysis. Dissertation for the degree of candidate of philosophical sciences in specialty 09.00.10. - "Philosophy of Education". Institute of Higher Education of the Academy of Pedagogical Sciences of Ukraine. - Kiev, 2008.

3. Sidorenko A.L. External independent assessment in Ukraine took place // Bulletin of testing and monitoring in education. - 2008. - No. 9. - S. 13-15.

4. Redden E. Access and Equity: A Comparative Perspective. Inside Higher Education. - 2008. m March 17. // [Electronic resource]. Available at: http://insidehighered.com/news/2008/03/17/fulbrig ht.

5. Belyakov A.A. Implementation of the ideas of the Bologna process: what is missing in Ukraine // Scientific notes of the KROK University. - 2008. m Issue. 18. - T. 1. - S. 50-58.

6. Annikova N.A. The quality of education in Russian higher education: socio-cultural reference points of transformation. Dissertation for the degree of candidate of sociological sciences. Novocherkassk, 2006 .-- 156 p.

7. Kagan M.S. Philosophy of culture. - SPb., 1996 .-$354 \mathrm{p}$.

8. Gershunsky B.S. Philosophy of Education for the 21st Century. - M., - 1998 .-- 478 p. 
9. Zimnyaya I.A. General culture and social and professional competence of a person // Higher education today. - 2005. - No. 11. - S. 19-27.

10. Yakovleva T.V. Model of the quality of higher education // Problems of education in modern Russia and the post-Soviet space. - Penza, 2004 .-$343 \mathrm{p}$.

11. Khomeriki, EA Main points of a sociological approach to modeling the quality of higher education. - 2013. - No. 11 (58). - S. 755-759.

12. Nuriddin Alikariev, Alohon Alikarieva, Umida Sabirova, Olimkhon Aliqoriev, Farogat Fayzieva. Quantitative Assessment of Factors of Improvement of Labor Efficiency in Higher Education Institutions. International Journal of Psychosocial Rehabilitation, Vol. 24, Special Issue 1, 2020. DOI: 10.37200 / IJPR / V24SP1 / PR201239 Received: 19 Jan 2020 | Revised: 08 Feb 2020 | Accepted: 27 Feb 2020. -P. 948. 